\title{
Extranodal extension status is a powerful prognostic factor in stage III colorectal cancer
}

\author{
Chan Wook Kim ${ }^{1}$, Jihun Kim², Seung-Seop Yeom ${ }^{1}$, Jong Lyul Lee ${ }^{1}$, Yong Sik Yoon ${ }^{1}$, \\ In Ja Park ${ }^{1}$, Seok-Byung Lim${ }^{1}$, Seunghee Baek ${ }^{3}$, Chang Sik Yu${ }^{1}$ and Jin Cheon Kim ${ }^{1}$ \\ ${ }^{1}$ Department of Surgery, University of Ulsan College of Medicine, Institute of Innovative Cancer Research, Asan Medical \\ Center, Seoul, Korea \\ ${ }^{2}$ Department of Pathology, University of Ulsan College of Medicine, Institute of Innovative Cancer Research, Asan Medical \\ Center, Seoul, Korea \\ ${ }^{3}$ Department of Clinical Epidemiology and Biostatistics, University of Ulsan College of Medicine, Asan Medical Center, Seoul, \\ Korea
}

Correspondence to: Jin Cheon Kim, email: jckim@amc.seoul.kr

Keywords: colorectal cancer, lymph node, extranodal extension, stage III, prognosis

Received: March 20, $2017 \quad$ Accepted: April 12, $2017 \quad$ Published: May 26, 2017

Copyright: Kim et al. This is an open-access article distributed under the terms of the Creative Commons Attribution License (CC-BY), which permits unrestricted use, distribution, and reproduction in any medium, provided the original author and source are credited.

\section{ABSTRACT}

Purpose: The present study aimed to evaluate the clinicopathologic characteristics of patients with extranodal extension (ENE) and the prognostic implications of ENE in stage III colorectal cancer (CRC).

Results: ENE was more frequent in younger patients and those with rectal cancer, higher $\mathbf{T}$ stage, higher $\mathbf{N}$ stage, lymphovascular invasion (LVI), and perineural invasion (PNI). Five-year disease-free survival (DFS) and overall survival (OS) were lower in patients with ENE-positive than in those with ENE-negative tumors (DFS, $66.4 \%$ vs. $80.1 \%$; and $0 S, 74.8 \%$ vs. $85.6 \%$, respectively; $P<0.001$ both). In multivariate analysis, pathologic stage, the presence of ENE, LVI, PNI, and no adjuvant chemotherapy were significant independent prognostic factors for DFS and OS. There were no statistically significant differences in DFS and OS between ENEpositive stage IIIB tumors and ENE-negative stage IIIC tumors.

Materials and Methods: The records of 1,948 stage III CRC patients who underwent curative surgery between January 2003 and December 2010 were retrospectively reviewed.

Conclusions: The presence of ENE is independently and significantly associated with lower DFS and OS rates after curative resection for stage III CRC. ENE status should be considered in both the pathologic report and CRC staging system.

\section{INTRODUCTION}

Since 1987, the American Joint Committee on Cancer (AJCC) and the Union for International Cancer Control (UICC) have promoted a worldwide taxonomy of cancer staging based on the tumor-node-metastasis (TNM) staging system. Traditional TNM staging strategies for colorectal cancer (CRC) place patients with mesenteric lymph node involvement into the stage III category. A tumor nodule in the pericolonic fat without histologic evidence of residual lymph node tissue is classified as a tumor deposit. Previously, it was not considered a positive lymph node [1]. However, in the absence of unequivocal lymph node metastases, tumor deposits are considered N1 (particularly N1c) according to the AJCC $7^{\text {th }}$ edition [2].

Patients with stage III CRC are a heterogeneous group, and not all of these patients require strong adjuvant chemotherapy. Some of these patients have a good prognosis, similar to that of patients with stage II CRC, whereas others have a poor prognosis. In the AJCC staging system, the number of metastatic lymph nodes is the most important factor affecting prognosis in patients with stage III CRC. However, a variety of prognostic factors were identified that can be used to refine nodal staging, such as the 
ratio of the number of metastatic lymph nodes to retrieved lymph nodes [3-5], the presence of micrometastasis [6, 7], and the number of analyzed lymph nodes [8].

The presence of extranodal extension (ENE) of metastatic lymph nodes recently emerged as an important prognostic factor in several types of malignancies [9-15]. However, the prognostic value of ENE in CRC has not been reported extensively, and few studies are based on a reliable number of patients.

In the present study, we evaluated the clinicopathologic significance of ENE and investigated its prognostic implications in stage III CRC.

\section{RESULTS}

\section{Patient characteristics}

Of the 1,948 patients analyzed in this study, 1153 $(59.2 \%)$ were male and $835(42.9 \%)$ had rectal cancer. The mean age was $60 \pm 11$ years (range, 19-89 years). ENE in a metastatic lymph node was identified in 854 patients (43.8\%). The mean follow-up interval was $62 \pm 34$ months.

\section{Clinicopathologic characteristics according to ENE status}

There were no significant differences in sex, s-CEA level, and histologic type between ENE-positive and ENEnegative patients. However, ENE was more frequent in younger patients and those with rectal cancer, a higher $\mathrm{T}$ stage, a higher N stage, lymphovascular invasion (LVI), or perineural invasion (PNI) (Table 1).

\section{Prognostic factors for DFS}

The 5-year DFS rate was lower in patients with ENE-positive tumors than in patients with ENE-negative tumors $(66.4 \%$ vs. $80.1 \%, P<0.001)$. Comparison of DFS rates according to stage showed that the 5-year DFS rate was lower in the ENE-positive group than in the ENEnegative group in stage IIIB $(66.0 \%$ vs. $80.1 \%, P<.001)$, whereas stage IIIA and IIIC patients showed similar DFS rates (ENE-positive vs. ENE-negative: stage IIIA, 86.3\% vs. $93.4 \%, P=0.067$; stage IIIC, $54.0 \%$ vs. $62.3 \%, P$ $=0.102$ ) (Figure 1). Univariate analysis showed that elevated s-CEA, high histologic grade, pathologic stage, presence of ENE, presence of LVI, presence of PNI, and no adjuvant chemotherapy were associated with poor DFS. In multivariate analysis, pathologic stage, presence of ENE, presence of LVI, presence of PNI, and no adjuvant chemotherapy were significant independent prognostic factors for DFS (Table 2).

\section{Prognostic factors for OS}

The 5-year OS rate was lower in patients with ENE-positive tumors than in patients with ENE-negative tumors $(74.8 \%$ vs. $85.6 \%, P<0.001)$. Comparison of OS rates according to stage showed that the 5-year OS was lower in the ENE-positive group than in the ENEnegative group in stage IIIB and stage IIIC (stage IIIB: $76.8 \%$ vs. $84.8 \%, P<0.001$; stage IIIC: $64.5 \%$ vs. $77.4 \%$, $P=0.034)$, whereas stage IIIA patients showed similar OS (ENE-positive vs. ENE-negative: $92.4 \%$ vs. 92.6\%, $P$ $=0.747$ ) (Figure 2). Univariate analysis showed that old age, elevated s-CEA, high histologic grade, pathologic stage, presence of ENE, presence of LVI, presence of PNI, and no adjuvant chemotherapy were associated with poor OS. In multivariate analysis, old age, pathologic stage, presence of ENE, presence of LVI, presence of PNI, and no adjuvant chemotherapy were significant independent prognostic factors for OS (Table 3).

\section{Comparison of survival according to stage and ENE status}

To investigate the prognostic effect of ENE in the different stages, univariate analysis of DFS and OS was performed according to a combination of stage and ENE status. In addition, multivariate analysis was performed after adjusting for age ( $<60$ vs. $\geq 60$ ), sex, s-CEA (normal vs. high), differentiation (well-differentiated, moderately differentiated vs. poorly differentiated, signet ring cell type, mucinous type), tumor location (colon vs. rectum), LVI status, PNI status, and adjuvant chemotherapy.

In univariate and multivariate analysis, there was no statistically significant difference in DFS and OS rate between ENE-positive stage IIIB tumors and ENEnegative stage IIIC tumors (HR for DFS: 0.964 (0.6301.473), $\mathrm{p}=0.865$, HR for OS: $0.725(0.468-1.123), \mathrm{p}=0.15)$ (Tables 4 and 5). Especially, hazard ratio of ENE-positive stage IIIB to ENE-negative stage IIIC tumors for DFS is close to 1 meaning their risks are no statistically different as well as clinically equivalent.

\section{DISCUSSION}

In the present study, the ENE rate was $43.8 \%$ for all stage III CRCs. Tumor stage was positively related to the incidence of ENE (22.5\% in stage IIIA tumors, $41.1 \%$ in stage IIIB, and $73.5 \%$ in stage IIIC). ENE was also associated with young age, rectal cancer, advanced $\mathrm{T}$ and $\mathrm{N}$ stages, and LVI/PNI. In a meta-analysis by Veronese et al. [16], the ENE rate was $45.7 \%$ for node-positive CRC and ENE was associated with high $\mathrm{T}$ stage, high-grade tumors, and advanced tumor stage. The incidence of ENE and the results of our study were consistent with those reported by Veronese et al., strongly suggesting that ENE is closely linked to tumor aggressiveness.

The presence of ENE in metastatic lymph nodes is a negative prognostic factor for cancers of several organs, including stomach [9, 17], esophageal [18], papillary thyroid [10], breast [12], bladder [11], and non-small cell 
Table 1: Clinicopathologic characteristics according to extranodal extension status

\begin{tabular}{|c|c|c|c|}
\hline & $\begin{array}{l}\text { Extranodal extension (-) } \\
(n=1094)\end{array}$ & $\begin{array}{c}\text { Extranodal extension }(+) \\
(n=854)\end{array}$ & $P$ value \\
\hline Sex & & & 0.747 \\
\hline Male & $651(59.5)$ & $502(58.8)$ & \\
\hline Female & $443(40.5)$ & $352(41.2)$ & \\
\hline Age, years & & & 0.015 \\
\hline Mean \pm SD & $60 \pm 11$ & $59 \pm 11$ & \\
\hline s-CEA level, ng/mL & & & 0.960 \\
\hline Mean \pm SD & $7.3 \pm 31.9$ & $7.4 \pm 25.8$ & \\
\hline Tumor location & & & 0.003 \\
\hline Colon & $657(60.1)$ & $456(53.4)$ & \\
\hline Rectum & 437 (39.9) & $398(46.6)$ & \\
\hline pT category & & & $<0.001$ \\
\hline $\mathrm{T} 1$ & $66(5.9)$ & $16(1.9)$ & \\
\hline $\mathrm{T} 2$ & $123(11.2)$ & $59(6.9)$ & \\
\hline T3 & $852(77.9)$ & $723(84.7)$ & \\
\hline $\mathrm{T} 4$ & $53(4.8)$ & $56(6.6)$ & \\
\hline $\mathrm{pN}$ category & & & $<0.001$ \\
\hline N1 & $901(82.4)$ & $456(53.4)$ & \\
\hline $\mathrm{N} 2$ & $193(17.6)$ & $398(46.6)$ & \\
\hline pStage & & & $<0.001$ \\
\hline IIIA & $175(16.0)$ & $51(6.0)$ & \\
\hline IIIB & $841(76.9)$ & $586(68.6)$ & \\
\hline IIIC & $78(7.1)$ & $217(25.4)$ & \\
\hline Histology & & & 0.191 \\
\hline WD/MD & $992(90.7)$ & $759(88.9)$ & \\
\hline $\mathrm{PD} / \mathrm{SRC} / \mathrm{Muc}$ & $102(9.3)$ & $95(11.1)$ & \\
\hline LVI & $374(34.2)$ & $378(44.3)$ & $<0.001$ \\
\hline PNI & & & $<0.001$ \\
\hline No & $890(81.4)$ & $620(72.6)$ & \\
\hline Yes & $183(16.7)$ & $219(25.6)$ & \\
\hline Unknown & $21(1.9)$ & $15(1.8)$ & \\
\hline Adjuvant CTx & & & 0.272 \\
\hline Yes & $960(87.8)$ & $735(86.1)$ & \\
\hline No & $134(12.2)$ & $119(13.9)$ & \\
\hline Recurrence & $199(18.2)$ & $272(31.9)$ & $<0.001$ \\
\hline \multicolumn{4}{|l|}{ Follow-up months } \\
\hline Median (range) & $64.8(0.3-154.5)$ & $60.8(0.5-152.4)$ & \\
\hline
\end{tabular}

SD: standard deviation; s-CEA: serum carcinoembryonic antigen; WD: well-differentiated; MD: moderately differentiated; PD: poorly differentiated; SRC: signet ring cell; Muc: mucinous; LVI: lymphovascular invasion; PNI: perineural invasion; CTx: chemotherapy. 
lung [14] cancers. In particular, the presence of ENE in penile cancer [13] and vulvar cancer [15] is also taken into account in the $7^{\text {th }}$ AJCC cancer staging system [2].

The standard definition of ENE is extracapsular growth of tumor cells, invasion of the perinodal fat, or continuous extranodal location of tumor cells. Some studies use alternative definitions. ENE has been defined as an extension of lymph node metastatic cells through the nodal capsule into the perinodal fatty tissue and/or extranodal location of tumor cells [19]. According to this definition, free tumor deposits may be included in the ENE-positive category. Therefore, we used the standard definition of ENE. However, in the above meta-analysis, stratification of patients according to the definition of ENE (classical vs. alternative definition) did not significantly change the survival outcomes [16].

The prognostic implication of ENE in CRC was investigated previously, with most studies reporting that ENE-positive status is associated with poor prognosis in CRC [16, 19-23]. In the present study, Kaplan-Meier survival curves showed significant differences in both DFS and OS between ENE-positive and ENE-negative patients.
Subgroup analysis indicated that the difference was more significant in stage IIIB cancers. However, there was a tendency towards different survival outcomes between ENEpositive and ENE-negative patients in stage IIIA and IIIC cancers. This result can be attributed to the relatively good prognosis of stage IIIA cancers and the small sample size for stage IIIC cancers. Multivariate analysis also showed that ENE-positive status was a statistically significant independent prognostic factor for poor DFS and OS.

In the multivariate analysis, stage, presence of LVI, presence of PNI, and no adjuvant chemotherapy were independent prognostic factors for poor DFS and OS. Pathologic stage is the most powerful prognostic factor $[2,24]$. The presence of LVI or PNI is considered a negative prognostic indicator according to previous studies [25-28]. It has been recognized since 1990 that adjuvant chemotherapy significantly improves the OS and DFS outcomes of stage III colorectal cancer patients [29-31]. Similarly, in the present study, multivariate analysis showed that lack of adjuvant chemotherapy was an independent prognostic factor for poor DFS and OS.

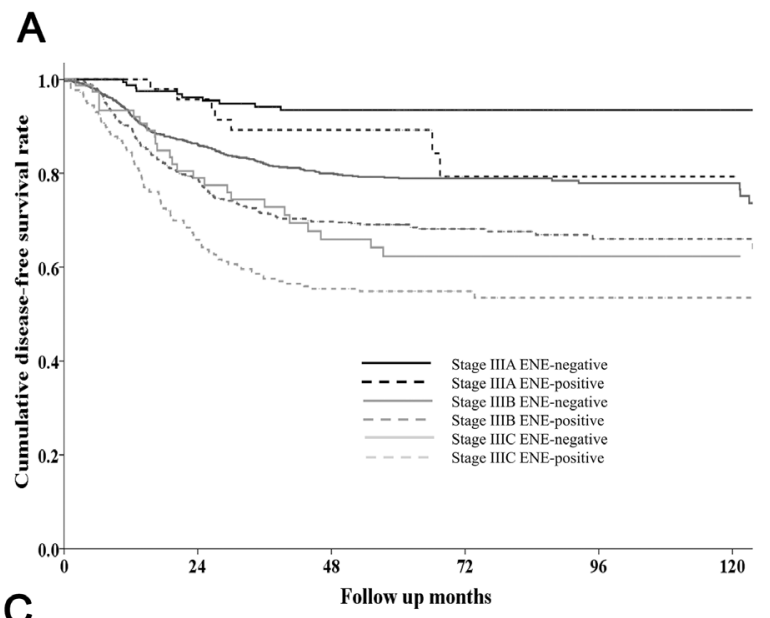

B
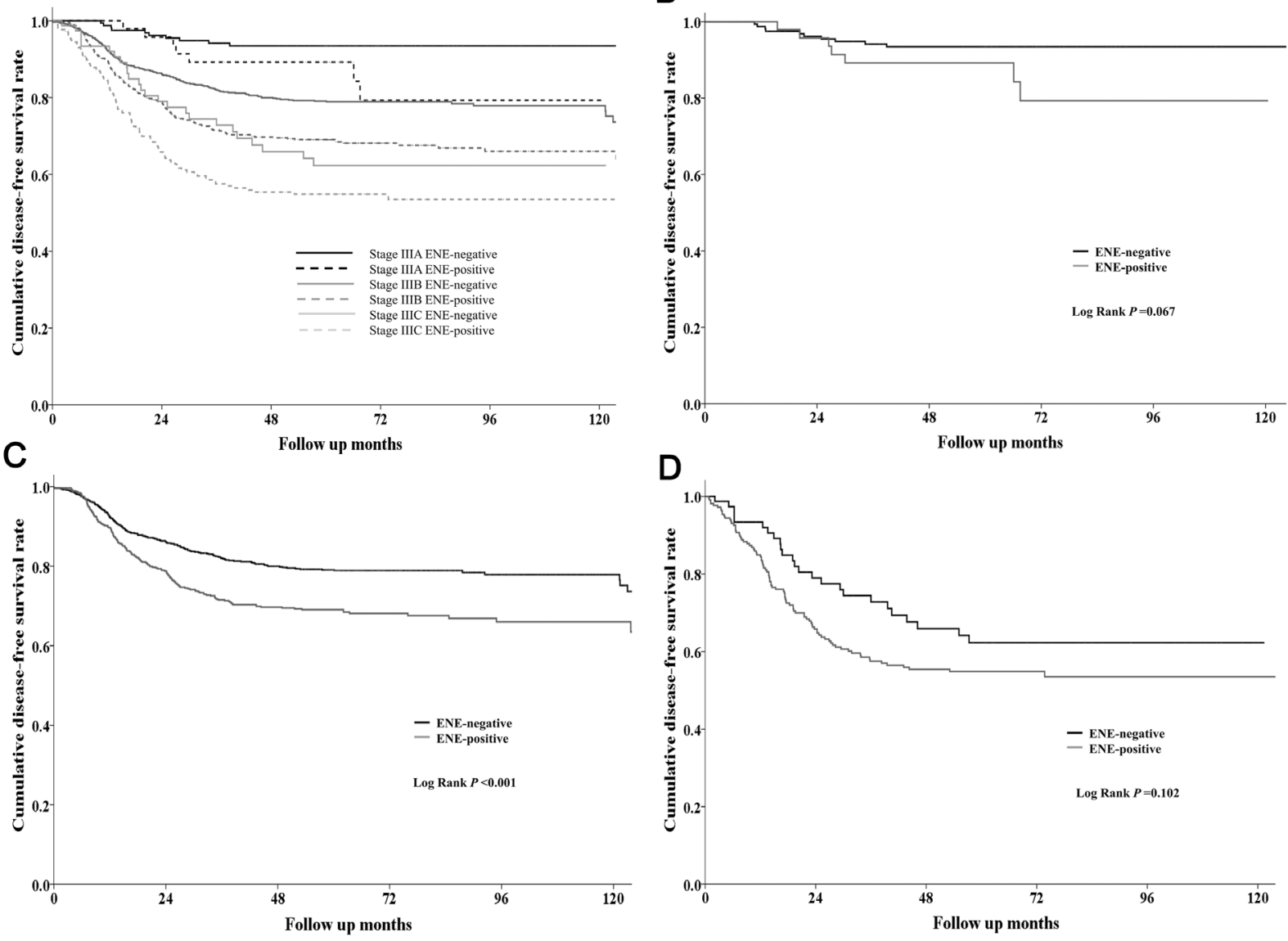

Figure 1: (A) Disease-free survival (DFS) rates according to the combination of stage and ENE status of stage III CRC patients. (B) DFS in stage IIIA patients with $(N=51)$ or without $(N=175)$ ENE. (C) DFS in stage IIIB patients with $(N=586)$ or without $(N=841)$ ENE. (D) DFS in stage IIIC patients with $(N=217)$ or without $(N=78)$ ENE. 
Table 2: Univariate and multivariate analysis of prognostic factors for disease-free survival (DFS) in patients with node-positive colorectal cancer

\begin{tabular}{|c|c|c|c|c|}
\hline \multicolumn{5}{|c|}{ Univariate analysis } \\
\hline Variable & & No. of patients & $\begin{array}{c}\text { 5-year } \\
\text { DFS rate }\end{array}$ & $P$ value \\
\hline \multirow{2}{*}{ Age (years) } & $<60$ & $897(46.0)$ & 76.1 & 0.094 \\
\hline & $\geq 60$ & $1051(54.0)$ & 72.2 & \\
\hline \multirow[t]{2}{*}{ Sex } & Female & $795(40.8)$ & 74.8 & 0.641 \\
\hline & Male & $1153(59.2)$ & 73.6 & \\
\hline \multirow[t]{2}{*}{ s-CEA } & Normal & $1552(79.7)$ & 75.3 & 0.013 \\
\hline & High & $396(20.3)$ & 69.0 & \\
\hline \multirow[t]{2}{*}{ Histology } & WD/MD & $1751(89.9)$ & 74.7 & 0.045 \\
\hline & $\mathrm{PD} / \mathrm{Muc} / \mathrm{SRC}$ & $197(10.1)$ & 68.6 & \\
\hline \multirow[t]{2}{*}{ Tumor location } & Colon & $1113(57.1)$ & 75.7 & 0.062 \\
\hline & Rectum & $835(42.9)$ & 71.8 & \\
\hline \multirow[t]{3}{*}{ pStage } & Stage IIIA & $226(11.6)$ & 92.0 & $<0.001$ \\
\hline & Stage IIIB & $1427(73.3)$ & 74.8 & \\
\hline & Stage IIIC & $295(15.1)$ & 56.9 & \\
\hline \multirow[t]{2}{*}{ Extranodal extension } & No & $1094(56.2)$ & 80.1 & $<0.001$ \\
\hline & Yes & $854(43.8)$ & 66.4 & \\
\hline \multirow[t]{2}{*}{ LVI } & No & $1196(61.4)$ & 79.6 & $<0.001$ \\
\hline & Positive & $752(38.6)$ & 65.3 & \\
\hline \multirow[t]{2}{*}{ PNI } & No & $1510(77.5)$ & 78.3 & $<0.001$ \\
\hline & Positive & $402(20.6)$ & 58.1 & \\
\hline \multirow[t]{2}{*}{ Adjuvant CTx } & No & $253(13.0)$ & 62.5 & $<0.001$ \\
\hline & Yes & $1695(87.0)$ & 75.5 & \\
\hline \multicolumn{5}{|c|}{ Multivariate analysis } \\
\hline Variable & & Hazard ratio & 95\% CI & $P$ value \\
\hline \multirow[t]{2}{*}{ s-CEA } & Normal & 1 & & 0.295 \\
\hline & High & 1.122 & $0.905-1.392$ & \\
\hline \multirow[t]{2}{*}{ Histology } & $\mathrm{WD} / \mathrm{MD}$ & 1 & & 0.426 \\
\hline & $\mathrm{PD} / \mathrm{Muc} / \mathrm{SRC}$ & 1.121 & $0.847-1.483$ & \\
\hline \multirow[t]{2}{*}{ Tumor location } & Colon & 1 & & 0.196 \\
\hline & Rectum & 1.154 & $0.960-1.387$ & \\
\hline \multirow[t]{3}{*}{ pStage } & Stage IIIA & 1 & & $<0.001$ \\
\hline & Stage IIIB & 2.813 & $1.717-4.609$ & \\
\hline & Stage IIIC & 3.612 & $2.120-6.155$ & \\
\hline \multirow[t]{2}{*}{ Extranodal extension } & No & 1 & & $<0.001$ \\
\hline & Yes & 1.507 & $1.245-1.826$ & \\
\hline \multirow[t]{2}{*}{ LVI } & Negative & 1 & & $<0.001$ \\
\hline & Positive & 1.490 & $1.227-1.808$ & \\
\hline \multirow[t]{2}{*}{ PNI } & No & 1 & & $<0.001$ \\
\hline & Positive & 1.652 & $1.351-2.020$ & \\
\hline \multirow[t]{2}{*}{ Adjuvant CTx } & No & 1 & & $<0.001$ \\
\hline & Yes & 0.583 & $0.457-0.743$ & \\
\hline
\end{tabular}

CI: confidence interval. 
Some authors wonder that ENE is important for both colon and rectal cancers $[32,33]$. We analyzed the DFS for both colon and rectal cancers separately. 5-year DFS rate was significantly lower in the patients with ENE both colon and rectal cancers, respectively (ENE-negative vs. ENE-positive; $81.2 \%$ vs. $68.0 \%, P<0.001$ ) (ENEnegative vs. ENE-positive; $78.3 \%$ vs. $64.9 \%, P<0.001)$ (Supplementary Figure 1). ENE may be an important prognostic factor for both colon and rectal cancers. The invasion by tumor cells of perinodal adipose tissue, indeed, is the same mechanism in both these locations that permits to the tumor to increase aggressiveness and metastatic potential. We will consider investigating the prognostic impact of ENE on colon and rectal cancer separately in our future study.

Taking the ENE status into consideration, DFS and OS were compared between stage IIIB and stage IIIC cancers. There were no statistically significant differences in DFS and OS between ENE-positive stage IIIB tumors and ENE-negative stage IIIC tumors. This suggests that the ENE status affects the staging system. Furthermore, the presence of ENE was more than $40 \%$ in stage III CRCs. This is another reason for which ENE should be considered by future staging system. The presence of ENE is not a rare condition. In line with the AJCC $7^{\text {th }}$ staging system, it is important to look for free tumor deposits in the subserosa, mesentery, or non-peritonealized pericolic or perirectal tissue $[2,34]$ in CRC and to assess ENE status in penile and vulvar cancer. The present findings suggest that ENE status in stage III CRC needs to be considered as an important factor in the staging system. In 2017, the AJCC $8^{\text {th }}$ edition [35] was published. However, the $8^{\text {th }}$ edition of AJCC staging manual also does not consider ENE status.

In conclusion, the presence of ENE was closely related to tumor aggressiveness in CRC. ENE was a significant independent prognostic factor for DFS and OS after curative resection for stage III CRC. ENE assessment should be included in histopathological evaluations and ENE status should be considered as part of the staging system for this disease.

\section{A}

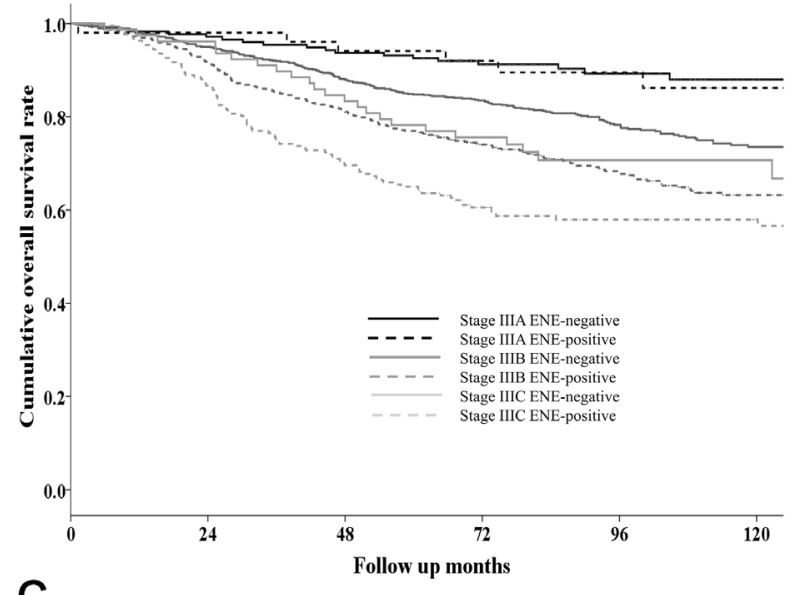

c

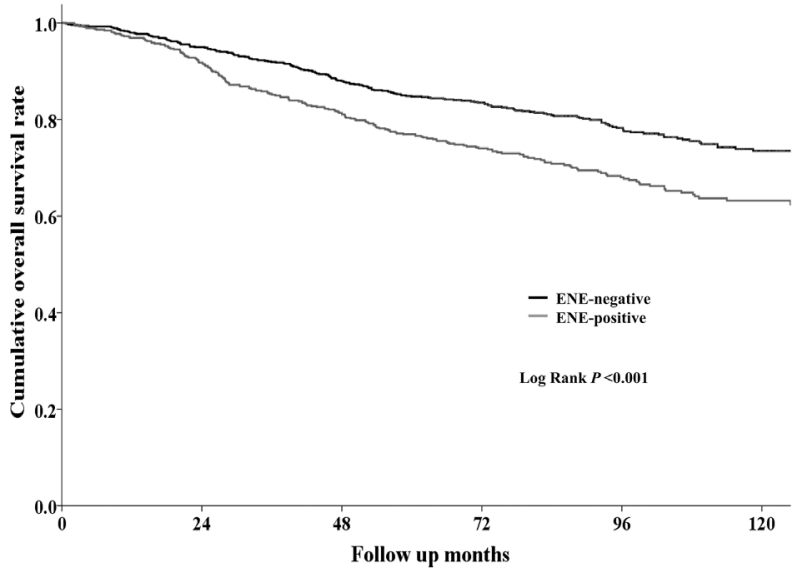

B

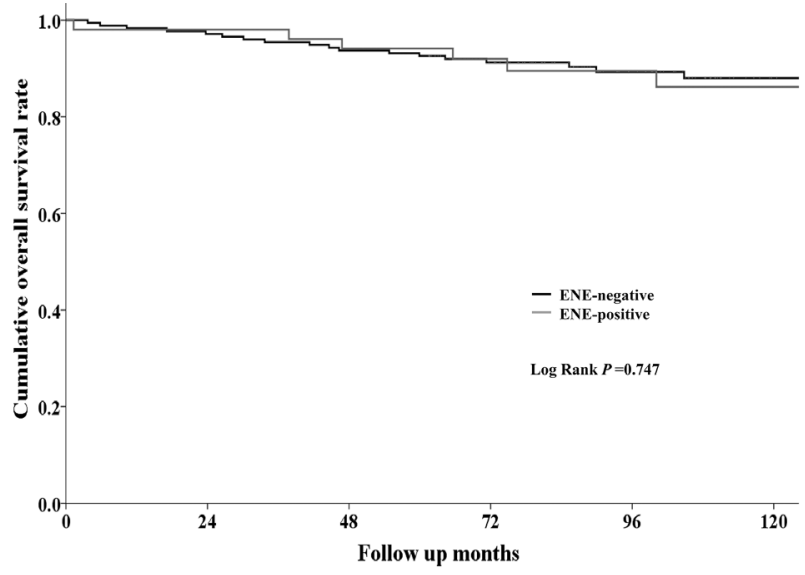

D

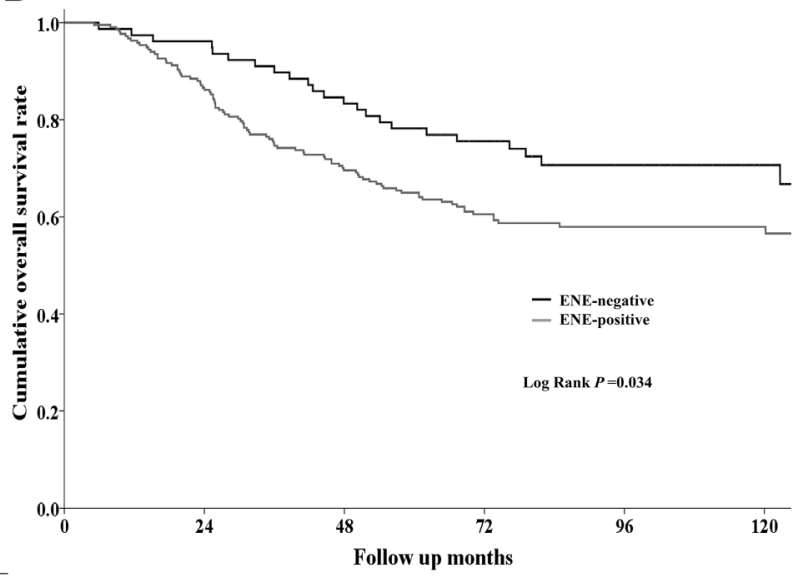

Figure 2: (A) Overall survival (OS) rates according to the combination of stage and ENE status of stage III CRC patients. (B) OS in stage IIIA patients with $(N=51)$ or without $(N=175)$ ENE. (C) OS in stage IIIB patients with $(N=586)$ or without $(N=841)$ ENE. (D) OS in stage IIIC patients with $(N=217)$ or without $(N=78)$ ENE. 
Table 3: Univariate and multivariate analysis of prognostic factors for overall survival (OS) in patients with nodepositive colorectal cancer

\begin{tabular}{|c|c|c|c|c|}
\hline \multicolumn{5}{|c|}{ Univariate analysis } \\
\hline Variable & & No. of patients & $\begin{array}{l}\text { 5-year } \\
\text { OS rate }\end{array}$ & $P$ value \\
\hline \multirow[t]{2}{*}{ Age (years) } & $<60$ & $897(46.0)$ & 85.7 & $<0.001$ \\
\hline & $\geq 60$ & $1051(54.0)$ & 76.4 & \\
\hline \multirow[t]{2}{*}{ Sex } & Female & $795(40.8)$ & 81.5 & 0.081 \\
\hline & Male & $1153(59.2)$ & 80.5 & \\
\hline \multirow[t]{2}{*}{ CEA } & Normal & $1552(79.7)$ & 81.9 & 0.011 \\
\hline & High & $396(20.3)$ & 76.8 & \\
\hline \multirow[t]{2}{*}{ Histology } & $\mathrm{WD} / \mathrm{MD}$ & $1751(89.9)$ & 82.0 & 0.020 \\
\hline & $\mathrm{PD} / \mathrm{Muc} / \mathrm{SRC}$ & $197(10.1)$ & 71.1 & \\
\hline \multirow[t]{2}{*}{ Tumor location } & Colon & $1113(57.1)$ & 82.1 & 0.089 \\
\hline & Rectum & 835 (42.9) & 79.3 & \\
\hline \multirow[t]{3}{*}{ pStage } & Stage IIIA & $226(11.6)$ & 92.9 & $<0.001$ \\
\hline & Stage IIIB & $1427(73.3)$ & 81.6 & \\
\hline & Stage IIIC & $295(15.1)$ & 68.0 & \\
\hline \multirow[t]{2}{*}{ Extranodal extension } & No & $1094(56.2)$ & 85.6 & $<0.001$ \\
\hline & Yes & $854(43.8)$ & 74.7 & \\
\hline \multirow[t]{2}{*}{ LVI } & No & $1196(61.4)$ & 85.7 & $<0.001$ \\
\hline & Positive & $752(38.6)$ & 73.3 & \\
\hline \multirow[t]{2}{*}{ PNI } & No & $1510(77.5)$ & 83.4 & $<0.001$ \\
\hline & Positive & $402(20.6)$ & 70.9 & \\
\hline \multirow[t]{2}{*}{ Adjuvant CTx } & No & $253(13.0)$ & 57.7 & $<0.001$ \\
\hline & Yes & $1695(87.0)$ & 84.4 & \\
\hline \multicolumn{5}{|c|}{ Multivariate analysis } \\
\hline Variable & & Hazard ratio & $95 \% \mathrm{CI}$ & $P$ value \\
\hline \multirow[t]{2}{*}{ Age (years) } & $<60$ & 1 & & $<0.001$ \\
\hline & $\geq 60$ & 1.685 & $1.390-2.043$ & \\
\hline \multirow[t]{2}{*}{ CEA } & Normal & 1 & & 0.206 \\
\hline & High & 1.140 & $0.930-1.398$ & \\
\hline \multirow[t]{2}{*}{ Histology } & $\mathrm{WD} / \mathrm{MD}$ & 1 & & 0.091 \\
\hline & $\mathrm{PD} / \mathrm{Muc} / \mathrm{SRC}$ & 1.260 & $0.964-1.646$ & \\
\hline \multirow[t]{3}{*}{ pStage } & Stage IIIA & 1 & & $<0.001$ \\
\hline & Stage IIIB & 1.906 & $1.281-2.836$ & \\
\hline & Stage IIIC & 2.405 & $1.542-3.753$ & \\
\hline \multirow[t]{2}{*}{ Extranodal extension } & No & 1 & & $<0.001$ \\
\hline & Yes & 1.527 & $1.276-1.826$ & \\
\hline \multirow[t]{2}{*}{ LVI } & Negative & 1 & & $<0.001$ \\
\hline & Positive & 1.502 & $1.250-1.805$ & \\
\hline \multirow[t]{2}{*}{ PNI } & No & 1 & & $<0.001$ \\
\hline & Positive & 1.596 & $1.311-1.942$ & \\
\hline \multirow[t]{2}{*}{ Adjuvant CTx } & No & 1 & & $<0.001$ \\
\hline & Yes & 0.346 & $0.283-0.423$ & \\
\hline
\end{tabular}


Table 4: Univariate and multivariate analysis (after adjusting for age, sex, s-CEA, differentiation, tumor location, LVI, PNI, and adjuvant chemotherapy) of DFS according to stage and ENE status

\begin{tabular}{|c|c|c|c|c|}
\hline \multicolumn{5}{|c|}{ Univariate analysis } \\
\hline Variable & Reference & Hazard ratio & $95 \% \mathrm{CI}$ & $P$ value \\
\hline IIIA_ENE (-) & & 0.171 & $0.090-0.323$ & $<0.001$ \\
\hline IIIA_ENE $(+)$ & & 0.404 & $0.190-0.859$ & 0.019 \\
\hline IIIB_ENE (-) & IIIB_ENE $(+)$ & 0.629 & $0.508-0.779$ & $<0.001$ \\
\hline IIIC_ENE (-) & & 1.111 & $0.730-1.689$ & 0.624 \\
\hline IIIC_ENE $(+)$ & & 1.587 & $1.232-2.044$ & $<0.001$ \\
\hline \multicolumn{5}{|c|}{ Multivariate analysis } \\
\hline Parameter & Reference & Hazard ratio & $95 \% \mathrm{CI}$ & $P$ value \\
\hline IIIA_ENE (-) & & 0.207 & $0.109-0.394$ & $<0.001$ \\
\hline IIIA_ENE $(+)$ & & 0.467 & $0.219-0.998$ & 0.049 \\
\hline IIIB_ENE (-) & IIIB_ENE $(+)$ & 0.657 & $0.529-0.815$ & $<0.001$ \\
\hline IIIC_ENE (-) & & 0.964 & $0.630-1.473$ & 0.865 \\
\hline IIIC $\operatorname{ENE}(+)$ & & 1.280 & $0.980-1.672$ & 0.070 \\
\hline
\end{tabular}

Table 5: Univariate and multivariate analysis (after adjusting for age, sex, CEA, differentiation, tumor location, LVI, PNI, and adjuvant chemotherapy) of OS according to stage and ENE status

\begin{tabular}{|c|c|c|c|c|}
\hline \multicolumn{5}{|c|}{ Univariate analysis } \\
\hline Variable & Reference & Hazard ratio & $95 \% \mathrm{CI}$ & $P$ value \\
\hline IIIA_ENE (-) & & 0.314 & $0.198-0.498$ & $<0.001$ \\
\hline IIIA_ENE $(+)$ & & 0.367 & $0.173-0.780$ & 0.009 \\
\hline IIIB_ENE (-) & IIIB_ENE $(+)$ & 0.651 & $0.532-0.795$ & $<0.001$ \\
\hline IIIC_ENE (-) & & 0.863 & $0.560-1.330$ & 0.504 \\
\hline IIIC_ENE $(+)$ & & 1.434 & $1.116-1.843$ & 0.005 \\
\hline \multicolumn{5}{|c|}{ Multivariate analysis } \\
\hline Parameter & Reference & Hazard ratio & $95 \% \mathrm{CI}$ & $P$ value \\
\hline IIIA_ENE (-) & & 0.373 & $0.234-0.594$ & $<0.001$ \\
\hline IIIA_ENE $(+)$ & & 0.436 & $0.205-0.930$ & 0.032 \\
\hline IIIB_ENE (-) & IIIB_ENE $(+)$ & 0.671 & $0.548-0.822$ & $<0.001$ \\
\hline IIIC_ENE (-) & & 0.725 & $0.468-1.123$ & 0.150 \\
\hline IIIC_ENE $(+)$ & & 1.301 & $1.000-1.692$ & 0.050 \\
\hline
\end{tabular}
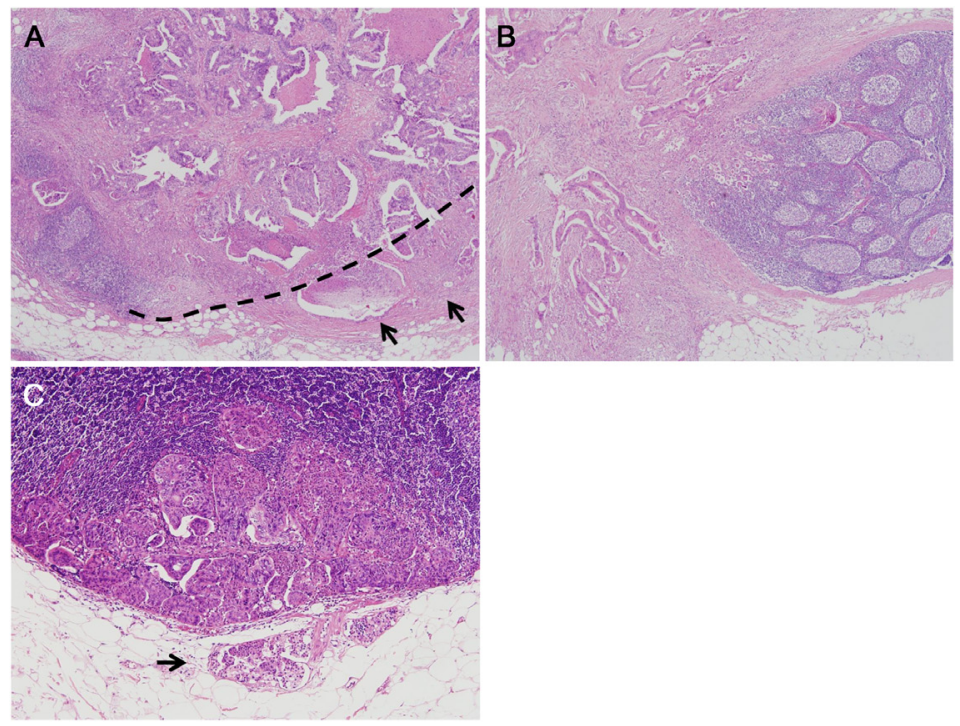

Figure 3: Representative examples of lymph node metastasis patterns. (A) Extranodal extension (ENE) positive: tumor cells invading fat tissue (arrows) beyond the boundary of the lymph node (dashed line) ( $\times 4$ objective lens). (B) Extranodal extension negative: tumor cells present outside the lymph node but continuous with the primary tumor ( $\times 4$ objective lens). (C) Extranodal extension negative: tumor cells present outside the lymph node but confined to endolymphatic spaces (arrow) $(\times 10$ objective lens). 


\section{PATIENTS AND METHODS}

\section{Patients}

The medical records and database of 1,948 CRC patients who underwent surgery at Asan Medical Center, Seoul, Korea, between January, 2003, and December, 2010, were retrospectively reviewed. All patients included in this study met the following criteria: (1) a diagnosis of stage III CRC, (2) histologically proven adenocarcinoma, and (3) history of curative resection (R0). Patients who received preoperative neoadjuvant therapy, those with hereditary CRC (familial adenomatous polyposis and hereditary nonpolyposis colorectal cancer) and those with multiple colorectal cancers were excluded.

\section{Evaluation}

Before surgery, all patients underwent a staging workup, including colonofiberscopy, chest radiography, computed tomography (CT) of the abdomen and pelvis, and measurement of serum carcinoembryonic antigen (s-CEA) levels. In some patients, positron emission tomography (PET) scan, single contrast-enhanced magnetic resonance imaging (MRI) of the liver, and/or chest CT scan were performed to further characterize the lesion's risk of malignancy. Serum CEA was measured by enzyme immunoassay (ELISA-2-CEA kit $\AA$; CIS Bio International, Marcoule, France). The normal s-CEA concentration was set at $\leq 6 \mathrm{ng} / \mathrm{mL}$. Tumors were pathologically staged in accordance with the cancer staging manual (AJCC $7^{\text {th }}$ edition).

\section{Histologic evaluation}

The ENE status of all specimens was examined by two pathologists, including a fellow and a faculty pathologist, and the final diagnosis was made on the basis of intradepartmental consultation with staff specialized in CRC. ENE was defined as cancer cells infiltrating the extranodal adipose tissue beyond the capsule of the lymph node (Figure 3A). Tumor cells that were present outside the lymph node and continuous with the primary tumor (Figure 3B) or confined to endolymphatic spaces (Figure 3C) were not considered ENE. In addition, tumor deposits, and clear lymphovascular or perineural invasion were not considered ENE. When lymphovascular invasion was equivocal, elastic staining, or immunohistochemistry for CD31 or D2-40 was generously performed. The tumor was considered ENE-positive when one or more of the metastatic lymph nodes showed ENE.

\section{Adjuvant chemotherapy}

Of the 1,984 patients in the study cohort, 1,780 $(91.4 \%)$ received postoperative chemotherapy as follows: 329 patients (16.9\%) received 5-fluorouracil; 821 (42.1\%) received capecitabine; $416(21.4 \%)$ received oxaliplatin; $96(4.9 \%)$ received an oral pyrimidine analogue or oral 5-fluorouracil; and $118(6.1 \%)$ patients received chemotherapy at another hospital. The remaining 168 patients $(8.6 \%)$ did not receive adjuvant chemotherapy. For data analysis, patients who received either 5 -fluorouracil-based chemotherapy intravenously or capecitabine-/oxaliplatin-based chemotherapy during the determined periods were considered as having complete adjuvant chemotherapy. Of the 835 rectal cancer patients, $330(39.5 \%)$ received postoperative radiotherapy.

\section{Follow-up}

Patients underwent a standardized postoperative follow-up (including clinical examinations, complete blood counts, blood chemistry tests, measurements of s-CEA levels, and chest radiography) every 3 months for the first 2 postoperative years and every 6 months thereafter. Patients also underwent abdominal and pelvic CT scan every 6 months. Colonoscopy was performed within 1 year of surgery and then once every 2-3 years. If recurrence was suspected, patients underwent CT scan, MRI, and/or PET scan. Recurrence was diagnosed pathologically (by surgical resection or biopsy) and/or radiologically.

\section{Statistical analysis}

Categorical variables were compared using chisquared tests, and continuous variables were compared using independent sample $t$-tests. The Kaplan-Meier method was used to compare disease-free survival (DFS) and overall survival (OS) rates. Univariate and multivariate analyses of factors associated with DFS rates were performed using Cox proportional hazards $(\mathrm{PH})$ regression analyses to estimate the hazard ratios and yield 95\% confidence intervals (CIs). All statistical tests were two-sided, and $P<0.05$ was considered statistically significant. Statistical analyses were performed using SPSS 21.0 for Windows (SPSS, Inc., Chicago, IL).

\section{CONFLICTS OF INTEREST}

The authors declare no conflicts of interest.

\section{FUNDING}

This work was supported by the grant (to J.C. Kim) from the Korea Research Foundation (2016R1E1A1A02919844), Ministry of Science, ICT, and Future Planning, Republic of Korea.

\section{REFERENCES}

1. Washington MK, Berlin J, Branton P, Burgart LJ, Carter DK, Fitzgibbons PL, Halling K, Frankel W, Jessup J, Kakar S, Minsky B, Nakhleh R, Compton CC. Protocol for the 
examination of specimens from patients with primary carcinoma of the colon and rectum. Arch Pathol Lab Med. 2009; 133:1539-1551.

2. Edge SB, Byrd DR, Compton CC, Fritz AG, Greene FL, Trotti AI. (2010). AJCC Cancer Staging Manual. (New York: Springer).

3. Rosenberg R, Friederichs J, Schuster T, Gertler R, Maak M, Becker K, Grebner A, Ulm K, Hofler H, Nekarda H, Siewert JR. Prognosis of patients with colorectal cancer is associated with lymph node ratio: a single-center analysis of 3,026 patients over a 25-year time period. Ann Surg. 2008; 248:968-978.

4. Kim YS, Kim JH, Yoon SM, Choi EK, Ahn SD, Lee SW, Kim JC, Yu CS, Kim HC, Kim TW, Chang HM. lymph node ratio as a prognostic factor in patients with stage III rectal cancer treated with total mesorectal excision followed by chemoradiotherapy. Int J Radiat Oncol Biol Phys. 2009; 74:796-802.

5. Park IJ, Yu CS, Lim SB, Yoon YS, Kim CW, Kim TW, Kim JH, Kim JC. Ratio of metastatic lymph nodes is more important for rectal cancer patients treated with preoperative chemoradiotherapy. World J Gastroenterol. $2015 ; 21: 3274-3281$.

6. Liefers GJ, Cleton-Jansen AM, van de Velde CJ, Hermans J, van Krieken JH, Cornelisse CJ, Tollenaar RA. Micrometastases and survival in stage II colorectal cancer. N Engl J Med. 1998; 339:223-228.

7. Yasuda K, Adachi Y, Shiraishi N, Yamaguchi K, Hirabayashi Y, Kitano S. Pattern of lymph node micrometastasis and prognosis of patients with colorectal cancer. Ann Surg Oncol. 2001; 8:300-304.

8. Le Voyer TE, Sigurdson ER, Hanlon AL, Mayer RJ, Macdonald JS, Catalano PJ, Haller DG. Colon cancer survival is associated with increasing number of lymph nodes analyzed: a secondary survey of intergroup trial INT0089. J Clin Oncol. 2003; 21:2912-2919.

9. Lee IS, Park YS, Ryu MH, Song MJ, Yook JH, Oh ST, Kim BS. Impact of extranodal extension on prognosis in lymph node-positive gastric cancer. Br J Surg. 2014; 101:1576-1584.

10. Suh S, Pak K, Seok JW, Kim IJ. Prognostic value of extranodal extension in thyroid cancer: a meta-analysis. Yonsei Med J. 2016; 57:1324-1328.

11. Fajkovic H, Cha EK, Jeldres C, Robinson BD, Rink M, Xylinas E, Chromecki TF, Breinl E, Svatek RS, Donner G, Tagawa ST, Tilki D, Bastian PJ, et al. Extranodal extension is a powerful prognostic factor in bladder cancer patients with lymph node metastasis. Eur Urol. 2013; 64:837-845.

12. Nottegar A, Veronese N, Senthil M, Roumen RM, Stubbs B, Choi AH, Verheuvel NC, Solmi M, Pea A, Capelli P, Fassan M, Sergi G, Manzato E, et al. Extra-nodal extension of sentinel lymph node metastasis is a marker of poor prognosis in breast cancer patients: a systematic review and an exploratory meta-analysis. Eur J Surg Oncol. 2016; 42:919-925.
13. Zhang ZL, Yu CP, Liu ZW, Velet L, Li YH, Jiang LJ, Zhou FJ. The importance of extranodal extension in penile cancer: a meta-analysis. BMC Cancer. 2015; 15:815.

14. Lee YC, Wu CT, Kuo SW, Tseng YT, Chang YL. Significance of extranodal extension of regional lymph nodes in surgically resected non-small cell lung cancer. Chest. 2007; 131:993-999.

15. Luchini C, Nottegar A, Solmi M, Sergi G, Manzato E, Capelli P, Scarpa A, Veronese N. Prognostic implications of extranodal extension in node-positive squamous cell carcinoma of the vulva: a systematic review and metaanalysis. Surg Oncol. 2016; 25:60-65.

16. Veronese N, Nottegar A, Pea A, Solmi M, Stubbs B, Capelli P, Sergi G, Manzato E, Fassan M, Wood LD, Scarpa A, Luchini C. Prognostic impact and implications of extracapsular lymph node involvement in colorectal cancer: a systematic review with meta-analysis. Ann Oncol. 2016; 27:42-48.

17. Etoh T, Sasako M, Ishikawa K, Katai H, Sano T, Shimoda T. Extranodal metastasis is an indicator of poor prognosis in patients with gastric carcinoma. Br J Surg. 2006; 93:369-373.

18. Luchini C, Wood LD, Cheng L, Nottegar A, Stubbs B, Solmi M, Capelli P, Pea A, Sergi G, Manzato E, Fassan M, Bagante F, Bollschweiler E, et al. Extranodal extension of lymph node metastasis is a marker of poor prognosis in oesophageal cancer: a systematic review with meta-analysis. J Clin Pathol. 2016. doi: 10.1136/jclinpath-2016-203830. [Epub ahead of print]

19. Fujii T, Tabe Y, Yajima R, Yamaguchi S, Tsutsumi S, Asao T, Kuwano H. Extracapsular invasion as a risk factor for disease recurrence in colorectal cancer. World $\mathrm{J}$ Gastroenterol. 2011; 17:2003-2006.

20. Kim H, Rehman A, Chung Y, Yi K, Wi YC, Kim Y, Jang K, Jang SM, Paik SS. Clinicopathologic significance of extranodal tumor extension in colorectal adenocarcinoma with regional lymph node metastasis. Gastroenterol Res Pract. 2016; 2016:5620765.

21. Heide J, Krull A, Berger J. Extracapsular spread of nodal metastasis as a prognostic factor in rectal cancer. Int $\mathrm{J}$ Radiat Oncol Biol Phys. 2004; 58:773-778.

22. Komori K, Kanemitsu Y, Kimura K, Sano T, Ito S, Abe T, Senda Y, Shimizu Y. Detailed stratification of TNM stage III rectal cancer based on the presence/absence of extracapsular invasion of the metastatic lymph nodes. Dis Colon Rectum. 2013; 56:726-732.

23. Wind J, ten Kate FJ, Kiewiet JJ, Lagarde SM, Slors JF, van Lanschot JJ, Bemelman WA. The prognostic significance of extracapsular lymph node involvement in node positive patients with colonic cancer. Eur J Surg Oncol. 2008; 34:390-396.

24. Siegel R, Naishadham D, Jemal A. Cancer statistics, 2013. CA Cancer J Clin. 2013; 63:11-30. 
25. Lim SB, Yu CS, Jang SJ, Kim TW, Kim JH, Kim JC. Prognostic significance of lymphovascular invasion in sporadic colorectal cancer. Dis Colon Rectum. 2010; 53:377-384.

26. Huh JW, Lee JH, Kim HR, Kim YJ. Prognostic significance of lymphovascular or perineural invasion in patients with locally advanced colorectal cancer. Am J Surg. 2013; 206:758-763.

27. Yang Y, Huang X, Sun J, Gao P, Song Y, Chen X, Zhao J, Wang Z. Prognostic value of perineural invasion in colorectal cancer: a meta-analysis. J Gastrointest Surg. 2015; 19:1113-1122.

28. Knijn N, Mogk SC, Teerenstra S, Simmer F, Nagtegaal ID. Perineural invasion is a strong prognostic factor in colorectal cancer: a systematic review. Am J Surg Pathol. 2016; 40:103-112.

29. Moertel CG, Fleming TR, Macdonald JS, Haller DG, Laurie JA, Goodman PJ, Ungerleider JS, Emerson WA, Tormey DC, Glick JH, Veeder, MH, Mailliard JA. Levamisole and fluorouracil for adjuvant therapy of resected colon carcinoma. N Engl J Med. 1990; 322:352-358.

30. O'Connell MJ, Laurie JA, Kahn M, Fitzgibbons RJ Jr, Erlichman C, Shepherd L, Moertel CG, Kocha WI, Pazdur R, Wieand HS, Rubin J, Vukov AM, Donohue JH, et al.
Prospectively randomized trial of postoperative adjuvant chemotherapy in patients with high-risk colon cancer. J Clin Oncol. 1998; 16:295-300.

31. Andre $\mathrm{T}$, Boni C, Mounedji-Boudiaf L, Navarro M, Tabernero J, Hickish T, Topham C, Zaninelli M, Clingan P, Bridgewater J, Tabah-Fisch I, de Gramont A. Oxaliplatin, fluorouracil, and leucovorin as adjuvant treatment for colon cancer. N Engl J Med. 2004; 350:2343-2351.

32. Luchini C, Nottegar A, Pea A, Solmi M, Stubbs B, Capelli P, Sergi G, Manzato E, Fassan M, Wood LD, Scarpa A, Veronese N. Extranodal extension is an important prognostic parameter for both colonic and rectal cancer. Ann Oncol. 2016; 27:955-956.

33. Huang Q, Qin X. Prognostic impact of extracapsular lymph node involvement in colorectal cancer. Ann Oncol. 2016; 27:955.

34. Goldstein NS, Turner JR. Pericolonic tumor deposits in patients with $\mathrm{T} 3 \mathrm{~N}+\mathrm{MO}$ colon adenocarcinomas: markers of reduced disease free survival and intra-abdominal metastases and their implications for TNM classification. Cancer. 2000; 88:2228-2238.

35. American Joint Commitee on Cancer. (2017). AJCC Cancer Staging Manual. (New York: Springer). 